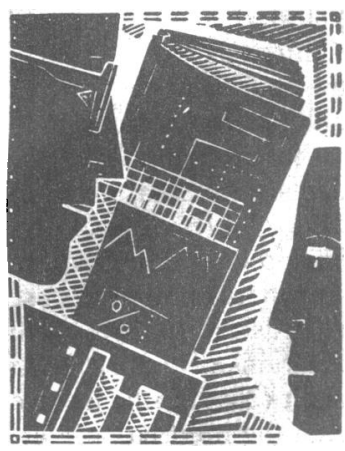

- This section is the first of a series on audit that will appear regularly in the journal. An editorial ( $p$ 65) gives further details about the series.

- In the first article Reeve et al describe the range of functions of a specialist transfer team in the west of Scotland. If specialist services are centralised existing transfer services will need upgrading. During three years the team transferred 378 critically ill patients, most of whom were mechanically ventilated. The findings support the feasibility of safe transfer of such patients and - In the second article Sharples et al determine the incidence of potentially avoidable factors associated with head injury in children, showing that in Northern region they still contribute to as many as 81 (32\%) deaths in this group.

- Dr Difford, in the first commissioned article, deals with defining essential data in general practice and Mr Collins, in the second, with regional specialty subcommittees and the organisation of audit.

Clinical Shock Study Group, Western Infirmary, Glasgow G11 6NT W G Reeve, FCANAES, registrar

C J Runcie, FCANAES, registrar

J Reidy, FRCSI, registrar P G $M$ Wallace, FCANAES, consultant anaesthetist

Correspondence to: Dr Reeve.

BrMed J 1990;300:85-7

\title{
Current practice in transferring critically ill patients among hospitals in the west of Scotland
}

\author{
W G Reeve, C J Runcie, J Reidy, P G M Wallace
}

\section{Abstract}

Objective-To identify the requirements of an interhospital transfer service for critically ill patients.

Design-Retrospective survey of the current functions of a specialist interhospital transfer team from data collected at the time of transfer and from records of intensive care unit.

Setting-Mobile intensive care unit based at a tertiary referral centre, which serves the west of Scotland.

Patients-All critically ill patients (378) transferred between hospitals by the unit from 1986 to 1988.

Results -365 Patients were transferred by road and 13 by air. There was a wide variation in age (range 6 weeks to 87 years), diagnosis, reason for transfer, support required, and distance travelled. Most patients (232) were transferred for respiratory or cardiovascular support; 100 were trauma cases. 300 Patients $(79 \%)$ were mechanically ventilated during transfer. No patient died in transit, although the eventual mortality was $28 \%$ (105 patients). Mortality was significantly higher in patients transferred from hospitals with intensive care units than from those without (38\% (125 patients) $v 23 \%$ (253); $\mathbf{p}<\mathbf{0 . 0 0 5}$ ).

Implications - Safe interhospital transfer of critically ill patients is feasible; the high eventual mortality in some patient groups emphasises the need for accurate prediction of outcome if inappropriate transfer is to be avoided. The findings may help in organising secondary transfer services in future.

\section{Introduction}

Debate continues about the need to centralise specialist medical services. Such centralisation would create a need for upgrading existing transfer services. A survey of 280 general intensive care units has shown that $8 \%$ of admissions are transferred among hospitals and that half the respondents considered the arrangements for transfer unsatisfactory.

The Glasgow Clinical Shock Study Group, based at this hospital, has been involved in secondary transfer of critically ill patients since 1974. Two doctors accompany the patient in a specially designed ambulance equipped as a mobile intensive care unit. Details of the equipment and the organisation of the service have been reported previously. ${ }^{2}$ By auditing its current functions our aims were to predict future demand in the west of Scotland, to identify trends in crossboundary flow in anticipation of the government's white paper Working for Patients, and also to give guidelines by which secondary transfer services may be organised in other areas.

\section{Patients and methods}

We collected data on all interhospital transfers done by the group over the three years 1986-8. Information such as the source of referral, destination, patient's age, sex, diagnosis, and support required was recorded at the time of transfer. We collected data on patient outcome later from intensive care unit records. Statistical analysis of variables associated with mortality was by the $\chi^{2}$ test.

\section{Results}

Table I indicates the steady increase in the annual number of transfers by the team since 1975 . The total number of transfer calls during the study period was 393 , in which 15 patients were assessed by the team but not transferred either because they died before transfer or because their condition deteriorated to the extent that transfer was no longer considered appropriate. Of the 378 patients remaining, 365 were transferred by road (range of distance 0.6 to $93.0 \mathrm{~km}$ ) and 13 by air.

Table II summarises the sources of referral and transfer destinations. The service was used by 38 different hospitals in 11 health boards. In 206 transfers $(55 \%)$, however, both the referral and destination hospitals were within the area of Greater Glasgow Health Board; $178(47 \%)$ transfers were to the base hospital (Western Infirmary).

The mean time taken for an ambulance transfer, including the outward journey to the referral hospital, preparation of the patient by the team, and return to base was three hours (range 50 minutes to 11 hours). The mean time taken to prepare the patient before 
transfer was about twice that of the return ambulance journey. Air transfers took a mean of nine hours (range six to 17 hours).

The mean age of the patients was 44.5 years (range 6 weeks to 87 years); 219 (58\%) were male and 159 $(42 \%)$ were female. Table III shows the monitoring and support procedures during transfer; oxygen saturation was monitored in all patients since the acquisition of a pulse oximeter in 1988. Table IV shows the number of patients transferred for regional services such as dialysis and to neurosurgical, paediatric, or burns units and also shows the small number transferred to supraregional transplant units in Newcastle upon Tyne or London. Most (232), however, were transferred for respiratory or cardiovascular support in general intensive care units (table $\mathrm{V}$ shows the principal diagnoses). This single diagnosis, however, con-

TABLE I - Transfers of critically ill patients 1975-88

\begin{tabular}{|c|c|c|c|c|c|c|c|c|c|c|c|c|c|}
\hline Year & 1975 & 1976 & 1977 & 1978 & 1979 & 1980 & 1981 & 1982 & 1983 & $1984^{\star}$ & 1986 & 1987 & 1988 \\
\hline No of transfers & 31 & 38 & 46 & 41 & 71 & 52 & 92 & 85 & 75 & 99 & 112 & 115 & 151 \\
\hline \multicolumn{14}{|c|}{$\star$ Data unavailable. } \\
\hline & & & & \multicolumn{10}{|c|}{$\begin{array}{l}\text { TABLE II-Source of referral and transfer destination with respect to } \\
\text { area covered by Greater Glasgow Health Board }\end{array}$} \\
\hline & & & & & & & & & & \multicolumn{4}{|c|}{ No of transfers } \\
\hline & & & & & & & & & & 1986 & 1987 & & 1988 \\
\hline & & & & $\begin{array}{l}\text { Source } \\
\text { Source } \\
\text { Source }\end{array}$ & $\begin{array}{l}\text { withir } \\
\text { outsid } \\
\text { end d }\end{array}$ & $\begin{array}{l}\text { 1, dest } \\
\text { le, des } \\
\text { estinat }\end{array}$ & $\begin{array}{l}\text { ination } \\
\text { tinatior } \\
\text { ion wit }\end{array}$ & $\begin{array}{l}\text { outsid } \\
\text { n withi } \\
\text { thin }\end{array}$ & & $\begin{array}{r}0 \\
56 \\
56\end{array}$ & $\begin{array}{r}7 \\
42 \\
66\end{array}$ & & $\begin{array}{l}14 \\
53 \\
84\end{array}$ \\
\hline
\end{tabular}

TABLE III-Monitoring and support procedures during transfer of 378 patients

\begin{tabular}{lc}
\hline & No $(\%)$ of patients \\
\hline Electrocardiography & 378 \\
Direct arterial pressure & $324(86)$ \\
Central venous or pulmonary artery catheter & $221(58)$ \\
Pulse oximetry & $161(43)$ \\
Intermittent positive pressure ventilation & $300(79)$ \\
Inotrope infusions & $98(26)$ \\
\hline
\end{tabular}

TABLE IV-Reasons for transfer by type of intensive care required at destination

\begin{tabular}{lcc}
\hline Type of intensive care & $\begin{array}{c}\text { No }(\%) \text { of } \\
\text { patients }\end{array}$ & Mortality $(\%)$ \\
\hline Respiratory or cardiovascular support & $232(61)$ & 23 \\
Renal & $61(16)$ & 54 \\
Neurosurgical & $58(15)$ & 24 \\
Paediatric & $19(5)$ & 11 \\
Burns & $4(1)$ & 50 \\
Cardiac transplantation & $2(<1)$ & 50 \\
Liver transplantation & $2(<1)$ & 50 \\
\hline Total & 378 & 28 \\
\hline
\end{tabular}

TABLE $\mathrm{v}$-Diagnoses in 232 patients transferred for respiratory or cardiovascular support

\begin{tabular}{lc}
\hline & No $(\%)$ of patients \\
\hline Trauma & $58(25)$ \\
Primary respiratory failure & $42(18)$ \\
Gastrointestinal disease or operation & $35(15)$ \\
Major sepsis & $30(13)$ \\
Neurological disease & $27(12)$ \\
Disease of or operation on cardiovascular system & $24(10)$ \\
Overdose & $7(3)$ \\
Other & $9(4)$ \\
\hline
\end{tabular}

TABLE VI - Deaths of transferred patients at destination by age

\begin{tabular}{lrrrrrrrrrr}
\hline Age (years) & $<13$ & $13-$ & $25-$ & $35-$ & $45-$ & $55-$ & $65-$ & $\geqslant 75$ & Unknown & Total \\
\hline No of patients & 19 & 59 & 47 & 45 & 57 & 80 & 47 & 15 & 9 & 378 \\
No of deaths & 2 & 12 & 6 & 14 & 22 & 28 & 14 & 3 & 4 & 105 \\
\hline
\end{tabular}

\section{Discussion}

Seriously ill patients have complications during interhospital transfer if they are not adequately prepared, monitored, and accompanied by trained medical staff. ${ }^{34}$ Proper management prevents such complications. ${ }^{5}$ In a previous study the mortality of 60 patients transferred by the Glasgow Clinical Shock Study Group to intensive care at the base hospital was not significantly different from that of comparably ill patients transferred to the same unit from within the hospital. ${ }^{6}$ Prognosis, as measured by sickness scoring and outcome, does not deteriorate during adequately managed transfer.?

The transfer team is contacted after a patient has been provisionally accepted by a recipient unit. In nearly all cases the recipient unit is one of five intensive care units in Glasgow that are all acquainted with the group. If after assessment by the team at the referral hospital there is doubt about the appropriateness of transfer senior staff at the recipient unit are consulted.

The criteria for using the group rather than an ordinary ambulance is the predicted need for cardiovascular or respiratory support during the journey. In most cases of head injury, however, the advantages of the group over a less specialist medical escort are outweighed by the delay incurred by the outward journey to the referral hospital. Hence most admissions to neurosurgical intensive care are brought by ordinary ambulance. The Association of Anaesthetists has recommended that the process of transfer should be the responsibility of the recipient unit. ${ }^{8}$ Transfers away from Glasgow (table II) are not in line with this recommendation, but in these cases the group was used because no comparable service was provided by the recipient units.

The high proportion of patients that required artificial ventilation, invasive monitoring, and inotropic support (table III) shows that medical staff with adequate training in intensive care are required for this kind of service and shows the need for portable, battery operated equipment including infusion pumps. The aim should be to meet the demands for changes in

veys no information on coexistent conditions. Twenty
five patients $(6 \%)$, for example, had recently had a Of the total group, 100 patients $(26 \%)$ were trauma admission after their injury. Thirty six $(61 \%)$ of these $23(39 \%)$ were patients with multiple trauma transferred from hospitals lacking facilities for mechanical ventila-
tion. The remaining 41 patients were transferred as non-acute cases, of whom, $23(56 \%)$ were postoperative
neurosurgical patients requiring prolonged ventilation, who were transferred to permit more appropriate use
of neurosurgical intensive care beds and $10(24 \%)$ were transferred because of complications of trauma, such holidaymakers transferred from the international airAlthough no patient died during transfer, the overall number of deaths in the destination unit was 105
$(28 \%)$. Of those dying in the intensive care unit at the base hospital (42), seven $(17 \%)$ patients did so within
24 hours after transfer. The number of deaths was generally lower in patients within the younger age
groups (table VI). The eventual mortality in ventilated patients was significantly higher than that in spon-
taneously breathing patients ( $31 \%$ ( 93 patients) $v 16 \%$ (12), $\left.\chi^{2}=7 \cdot 52 ; \mathrm{p}<0 \cdot 05\right)$. The mortality was significantly higher in patients transferred from hospitals
with intensive care units than from those without $(38 \%$ (125 patients) $v 23 \%$ (253), $\left.\chi^{2}=10 \cdot 03 ; \mathrm{p}<0.005\right)$. 
treatment during the journey rather than relying on the speed of the ambulance. The prolonged periods away from the base hospital suggest that a transfer service with medical staff covering emergencies within the hospital would be unsatisfactory. The group consists of registrars who have completed their fellowship examinations (two anaesthetists and one surgeon) whose main clinical responsibility is that of the mobile intensive care unit. At least one, and usually two, of the team are available for transfers 24 hours a day without depleting emergency cover at the base hospital.

The increasing use made of the service (table I) partly represents an increased awareness of its existence and appreciation of the requirements for safe transfer. This trend should be taken into account when planning secondary transfer services. Although the recent increase has been mainly in local transfers the variety of destinations and cross boundary flow is greater than in previous years. ${ }^{2}$ The transfer of patients to liver and cardiac transplant units is a recent phenomenon, with important funding implications. These transfers are costly in time and resources and require critical evaluation. The mobile intensive care service is funded by the Greater Glasgow Health Board. At present, no per head reimbursement is provided by other health boards, but detailed costs are currently being calculated before implementation of the government white paper.

A secondary transfer service should be tailored to the geography, population, and distribution of services in its area. Glasgow has special needs, firstly, because it is a referral centre for large sparsely populated areas of Scotland, and, secondly, because its regional services are distributed in different hospitals around the city.
This contrasts with the recommendations for regional trauma units, ${ }^{9}$ but the group does allow safe transfer among hospitals.

The favourable mortality in the over 75 age group (table VI) implies that age alone should not exclude patients from transfer for intensive care. The higher mortality in patients transferred from other intensive care units is interesting. Patients already receiving intensive care in whom deterioration precipitates transfer to a more specialist unit may well have a poorer prognosis than those transferred at an earlier stage of disease. Despite the absence of deaths in transit, the high eventual mortality in some patient groups reinforces the need for accurate prediction of outcome ${ }^{10}$ if inappropriate transfer is to be avoided.

1 Wright IH, McDonald JC, Rogers PN, Ledingham IMcA. Provision of right IH, McDonald JC, Rogers PN, Ledingham IMcA. Provision of facilities for secondary transport of

2 Ledingham IMcA, Banks JG. Movement of the critically ill patient. Hospital Update 1980;January 1980 Vol 6:43-9.

3 Olson CM, Jastremski MS, Vilogi JP, Madden CM, Beney KM. Stabilization of patients prior to interhospital transfer. Am f Emerg Med 1987;5:33-9.

4 Bion JF, Wilson IH, Taylor PA. Transporting critically ill patients by ambulance: sickness scoring. $\mathrm{Br}$ Med $\mathcal{F}$ 1988;296:170.

5 Waddel G, Scott PDR, Lees NW, Ledingham IMcA. Effects of ambulance ransport in critically ill patients. Br Med $\mathcal{F} 1975 ;$; :386-9.

6 Ridley S, Carter R. The effects of secondary transport on critically ill patients. Anaesthesia 1989;44:822-7.

7 Bion JF, Edlin SA, Ramsay G, McCabe S, Ledingham IMcA. Validation of a prognostic score in critically ill patients undergoing transport. $\mathrm{Br} \mathrm{Med} \mathcal{F}$ 1985;291:432-4.

8 Association of Anaesthetists of Great Britain and Ireland. Intensive care services - provision for the future. London: Association of Anaesthetists, 1988 9 Commission on the Provision of Surgical Services. Report of the working party on the management of patients with major injuries. London: Royal College of Surgeons, 1988.

10 King's Fund Panel. Intensive care in the United Kingdom. Anaesthesia 1989:44:428-31. (Report.)

(Accepted 23 October 1989)

\title{
Avoidable factors contributing to death of children with head injury
}

\author{
P M Sharples, A Storey, A Aynsley-Green, J A Eyre
}

\begin{abstract}
Objective-To assess the incidence of potentially avoidable complications contributing to death of children with head injuries.

Design-Retrospective review of children who died with head injuries from 1979 to 1986 from data of the Office of Population Censuses and Surveys, Hospital Activity Analyses, case notes, coroners' records, and necropsy reports.
\end{abstract}

Setting-District general hospitals and two regional neurosurgical centres in Northern region.

Results -255 Children died from head injury in the region, the mortality being 5.3 per 100000 children per year. Head injury was the single most important cause of death in children aged $>1$ year, accounting for $15 \%$ of deaths in children aged 1-15 years and a quarter for those aged 5-15 years. 121 Potentially avoidable factors possibly or probably contributing to death occurred in 81 children $(32 \%)$. Half the children (125) died before admission, 27 of whom $(22 \%)$ had potentially avoidable factors possibly or probably contributing to death, and 130 died after admission, 54 of whom (42\%) had 93 such factors, which included failure of diagnosis or delayed recognition of intracranial haemorrhage or associated injury, inadequate management of the airways, and poor management of the transfer between hospitals.

Implications-Regions should revise urgently their guidelines for optimal management and indications for neurosurgical referral to include children with severe head injuries and audit their systems of care for all patients with head injuries.

\section{Introduction}

Trauma and particularly head injury are well recognised as the major cause of death in children aged over 1 year. ${ }^{12}$ The mortality reported from specialist neurosurgical centres after severe head injury in childhood ranges from $6 \%$ to $35 \% .^{3.5}$ Although these widely differing values probably reflect varying patterns of referral rather than different approaches to management, ${ }^{6}$ Bruce et al suggested that the mortality for children in hospital with severe head injury should not exceed $10 \%$ and implied that in centres with a higher mortality factors contributing to the deaths of some children may be avoidable with a more aggressive approach to management.

Previous studies of the management of adults and children with fatal head injuries indicate that up to $30 \%$ of those who died have had potentially avoidable secondary complications that probably contributed to death; these complications include delay before evacuation of intracranial haematomas, ${ }^{8}$ secondary brain damage caused by hypoxia and hypotension, ${ }^{910}$ uncontrolled convulsions, ${ }^{11}$ and complications of general anaesthesia. ${ }^{12}$ Most of the subjects have been adults, with children constituting only a small proportion. Although the probability of secondary complications is different in children compared with adults, ${ }^{1314}$ 